ISAHP 2005, Honolulu, Hawaii, July 8-10, 2003

\title{
ENHANCEMENT OF FINANCIAL RISK MANAGEMENT WITH THE AID OF ANALYTIC HIERARCHY PROCESS
}

\author{
Jerzy Michnik ${ }^{\mathrm{a}, \mathrm{b}, 1}$, Mei-Chen Lo ${ }^{\mathrm{c}}$ \\ ${ }^{a}$ Kainan University, No.1, Kainan Rd., Luchu, Taoyuan,338, Taiwan \\ ${ }^{\mathbf{b}}$ The K. Adamiecki University of Economics in Katowice, ul. 1 Maja 15, 40-287 Katowice, Poland \\ 'Institute of Technology Management, National Chiao Tung University \\ 1001, University Road, Hsin-Chu 300, Taiwan \\ jmichnik@ae.katowice.pl,mjlo.mt90g@nctu.edu.tw
}

Keywords: Analytic Hierarchy Process (AHP), Multiple Attribute Decision Making (MADM), financial risk management (FRM)

Summary: Rapid growth in financial markets, increasing volatility and globalization are the main reasons of growing importance of financial risk management (FRM) which nowadays becomes a serious matter not only for financial institution. Several risks, possible targets and measures of each dimension of risk, several types of tools and techniques come together to form the FRM. This is the reason why this is a complicated, multi-step and multidimensional process. This study aims at the four aspects of FRM: measuring, monitoring, controlling and policy to determine the participant cognition of relative importance (weight). The AHP approach is proposed to determine the relative importance of different aspects of FRM and to enhance the performance of the FRM.

\section{Introduction}

Financial risk is at the core of the business of finance. Financial risk management has become a vital topic not only for financial institutions but also for other types of business like manufacturing companies. Comprehensive FRM systems, linked with general strategic management (Ward and Grundy, 1996), are important in building stable framework for firm's development. They should comprise various risks and dynamically balance the firm's operations and activities to achieve the firm's objectives in the extended time periods. The different approach can be applied to such kind of task. The multi-stage stochastic model for supporting FRM is one of the examples (Mulvey et al., 1997). The same approach to combined financial planning and risk management is still a challenge for the computational operations research (Mulvey and Shetty, 2004).

Increasingly exposed to the pervasive risks of a rapidly changing global economy companies should continuously improve their FRM process. This compelling and important issue is a subject of this study which presents a vision of FRM enhancement.

Using advanced financial theory and modern information technology to temper basic risks enforces vitality of industry and the stability of national economies. Supported by a comprehensive information database, FRM can penetrate global markets for hedging opportunities and exploiting myriad new financial instruments. Presented approach shows how corporate-level FRM considerations can handle the financial risk on both operational and strategic level.

When the company reaches the stage of establishing or improves their FRM it faces the problem of choosing most suitable system. As no ideal system exists, the company has to trade-off between different

\footnotetext{
${ }^{1}$ Corresponding author.
} 
attributes of FRM. Then the performance evaluation may be of great help to achieve well-matched system for the particular company.

\section{Financial Risk Management}

A modern financial system goes very far in providing opportunities for shedding risk through diversification. It provides not only equity securities, but also a host of other financial assets - like bonds, bills, notes, financial instruments - like derivatives - all of varying degrees of risk. The vast proliferation of financial instruments, institutions, and markets which is seen in modern financial systems, along with the substantial resources devoted to them, all testify about the value of the financial risk management (for the review of the historical perspectives on financial systems, risk management and entrepreneurship see Sylla, 2003).

Corporate finance has its range of issues which interrelate financial markets and also competitive strategies. FRM process should match external sources of finance and strategies for corporate development. The maturity of the organization facilitate attaining financial information and ensure appropriate capital structure, as well raises the level of financial sophistication which is eligible by these industrial sectors which are characterized by high level of return. Still it is an open question how to link business and finance strategies while comply the financial risk.

Any organization has a range of stakeholders who have a specific and conspicuous interest in the outcomes of the corporate operations, the manner in which the business is conducted, and the strategic direction of the enterprise. These stakeholders may be identified as founders, owners, mangement, employees, customers, regulators, and the greater community. The aggregate sum of values, beliefs, and expectations of these diverse groups will determine the cultural profile of the organization. Steping down to the FRM level it takes shape of the systematic procedures of taking, measuring and controling financial risk. Clarke and Varma (1999) outlines a structured methodology for risk management process evaluation and change. In their proposal important role is played by "Evaluation and Improve Performance and Process" which is a kind of feedback in continuous improvement of risk management procedure. In this paper we present the comprehensive approach for this stage of building strategic risk management system.

\section{Methodology}

This section introduces the theory and the implementation of AHP method, and then establishes the model for the study objects. The designs are based on the FRM related models and catch up with practice via issuing questionnaire with the choice of the object and the level. Then the performance measure analysis and the ranking are carried on, followed by expert interviews for results confirmation and data correction of the research analysis.

\subsection{Construction of the Hierarchy System}

A decision-maker bases judgment on knowledge and experience, and then makes decisions accordingly. The finance community stresses the critical role-played by top management in effective implementation, therefore, managers are faced with decision environments and problems in organizations that are complex, where there are many interrelated issues. Brainstorming used to share ideas and insights often lead to a more complete representation and understanding of the issues. The brainstorming approach is a common way to aggregate ideas for decision-making. The AHP allows group decision-making, where group members can use their experience, values and knowledge to break down a problem into a hierarchy and solve it by the AHP procedure. The model consists of three steps: (1) situation description; (2) construction the correlation tree structure of multiple evaluation phases and evaluation criterions; (3) carrying out questionnaire design, the investigation and analysis through experts' brainstorming and 
discussion. AHP is essentially a data-weighting technique and its framework is utilized to formalize principles by which database semantics can be identified and compared with the real world.

\subsection{Evaluation aspects and criteria}

This paper considers the structure (Allen, 1994) and the concepts (Tzeng, 1977; Tzeng and Shiau, 1987; Tzeng et al., 1992; Tzeng and Teng, 1994) which establish the multi-criteria model in quantitative view of the study objects. This study incorporates the four-aspect representation of FRM. Figure 1 shows an evaluation hierarchy structure and its various levels as it was presented in a questionnaire. This aims at the measuring, monitoring, controlling and policy, which are the four phases to determine the participant cognition of relative importance (weight).

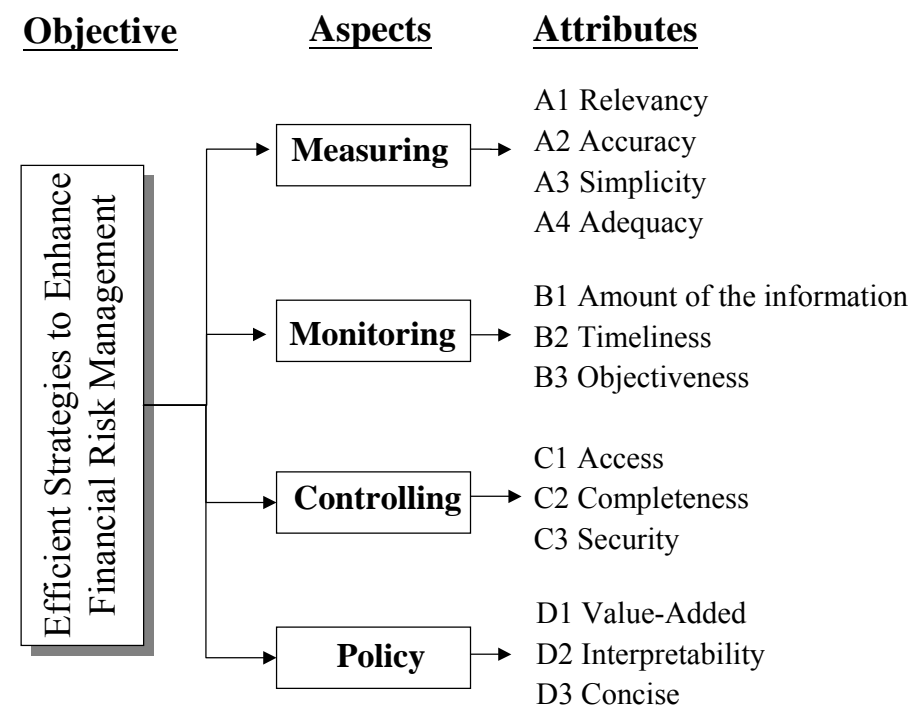

Figure 1. Hierarchy structure with weights

In order to aggregate the synthetic performance value of all possible alternatives/strategies in multiple attribute decision-making (MADM) problems, we ought firstly to determine the required information about the relative importance/weight of each criterion/attribute.

\subsection{Weight Measure}

The application of AHP for group decision-making environments involves defining a common hierarchy of criteria, specifying pair-wise comparisons by criteria in the group and aggregating those pair-wise comparisons for the entire group. Saaty (1980) used the principal eigenvector of the comparison matrix to find the comparative weights among the criteria of the hierarchy systems. We denote the criteria by $C_{1}, C_{2}, \ldots, C_{n}$ and their weights by $w_{1}, w_{2}, \ldots, w_{n}$. If $\boldsymbol{w}=\left(w_{1}, w_{2}, \ldots, w_{n}\right)^{T}$ is given, then the pair-wise comparisons may be represented by matrix $\boldsymbol{A}$ in the following formula:

$$
\left(A-\lambda_{\max } I\right) w=0
$$

Eq.(1) denotes that $\boldsymbol{A}$ is the positive reciprocal matrix of pair-wise comparison values derived by intuitive judgment for ranking order. In order to derive the priority eigenvector, we must find the eigenvector $w$ with respective $\lambda_{\max }$ that satisfies $A \boldsymbol{w}=\lambda_{\max } \boldsymbol{w}$. Saaty suggested using the consistency index (C.I. $=$ 
$\frac{\lambda_{\max }-n}{n-1}$ ) to test the consistency of the intuitive judgment. In general, a value of C.I. which is less than 0.1 , is satisfactory.

In addition to Saaty's method for aggregating the relative weights by participating evaluators, AHP's main purpose is to assist decision-makers in analyzing complex problems. This method first simplifies a complex decision-making problem into several distinct hierarchical levels, then combines the expert and participants opinions for the decision-maker, using a scaling type of questionnaire to proceed among factors or levels rated by pair-wise comparison. The pair-wise reciprocal matrix and an eigenvector for each factor after pair-wise comparison are calculated. This set the priority within certain hierarchy level and shows the relative importance among the factors. After calculating eigenvector of various factors the maximization of eigenvalue is performed for the comparison matrix $\lambda_{\max }$. This allows us to appraise the content of matrix whether it has the uniformity and whether its uniformity is strong or weak. In general, the decision-making part of AHP hierarchy structure consists of at least two levels. At each level the weights are calculated starting from the top. Next the priority of each factor is determined and how the factor of the lowest level impacts the whole hierarchy. AHP is a hierarchy structure that simultaneously measures and considers both quantified factors and non-quantified factors. Then, by collection of the expert opinions and the experience sharing, it generates the order with reference to the decision-maker. This method contains four issues concerning the evaluation of the complex question by giving systematic structure (Saaty and Vargas, 1980):

(1) establishing hierarchical structure;

(2) establishing evaluation scaling for each factor and setting up a pair-wise comparison matrix;

(3) calculation the relative weights of various factors;

(4) testing the uniformity.

The evaluation value, which is calculated from performance value and weight, indicates space for the improvement and the level of efficiency of IQ system.

Synthetic performance value - a weighted sum of performance values - is given by formula

$$
\mathrm{SPV}_{i}=\sum_{j=1}^{n} P V_{i j} \otimes \boldsymbol{w}_{j}, \quad i=1,2, \cdots, m
$$

The measures $P V_{i j}$ represent the performance value; where $i=1,2,3, \mathrm{j}=1,2,3,4 . i$ - the index for numbering groups, functions, units; $j-$ index for aspects in hierarchy structure. They are obtained from the original questionnaire survey and expert interviews by using the method of fuzzy triangle. Then crisp values are calculated for the recognition of criteria. Eq. (2) provides an indicator of future improvement space and shows how a strong consensus can arise in a set of grouped people.

\section{Empirical survey}

This study examines how the importance of FRM is seen from different points of view. The people who were interviewed were belonged to three categories of positions in companies: finance, management and engineering which are denoted as $X_{1}, X_{2}$ and $X_{3}$.

\subsection{Analysis}

Since the FRM system is important for operation planning and control activities in a company, the support for its configuration, operation and the fundamental financial information infrastructures should be introduced. Different analysis dimensions can help to see the real meaning of the effects which influent strategies on FRM.

Overall performance measure. 
The performance value provides correlations between importance (weight) and the satisfaction level of participants, which helps to indicate the FRM performance inside the company.

Table 1. The Weight by Aspects

\begin{tabular}{ccccc}
\hline & Measuring $\left[w_{1}\right]$ & Monitoring $\left[w_{2}\right]$ & Controlling $\left[w_{3}\right]$ & Policy $\left[w_{4}\right]$ \\
\hline$X_{1}$ & $0.319(1)$ & $0.181(4)$ & $0.264(2)$ & $0.236(3)$ \\
$X_{2}$ & $0.280(2)$ & $0.234(3)$ & $0.302(1)$ & $0.184(4)$ \\
$X_{3}$ & $0.358(1)$ & $0.224(3)$ & $0.287(2)$ & $0.131(4)$ \\
\hline Avg. & $0.320(1)$ & $0.213(3)$ & $0.287(2)$ & $0.180(4)$ \\
\hline
\end{tabular}

Table 2. Overall performance measure responses

\begin{tabular}{|c|c|c|c|c|c|c|c|c|c|}
\hline & $\begin{array}{l}\text { Mea } \\
\mathrm{PV}_{1}\end{array}$ & $\begin{array}{l}\text { uring } \\
\mathrm{PV}_{1} \times \mathrm{w}_{1}\end{array}$ & \multicolumn{2}{|c|}{$\begin{array}{l}\text { Monitoring } \\
\mathrm{PV}_{2} . \mathrm{PV}_{2} \times \mathrm{W}_{2}\end{array}$} & \multicolumn{2}{|c|}{ Controlling } & \multicolumn{2}{|c|}{$\begin{array}{c}\text { Policy } \\
\mathrm{PV}_{4} \cdot \mathrm{PV}_{4} \times w_{4}\end{array}$} & $S P V^{*}$ \\
\hline$X_{1}$ & 47.50 & $15.14(1)$ & 45.00 & $8.16(4)$ & 48.33 & $12.78(2)$ & 51.67 & $12.17(3)$ & 48.25 \\
\hline$X_{2}$ & 61.25 & $17.12(2)$ & 56.67 & $13.24(3)$ & 61.67 & $18.65(1)$ & 61.67 & $11.36(4)$ & 60.38 \\
\hline$X_{3}$ & 70.00 & $25.09(1)$ & 74.17 & $16.60(3)$ & 78.33 & $22.45(2)$ & 68.33 & $8.96(4)$ & 73.10 \\
\hline Avg. & 59.58 & $18.22(1)$ & 58.61 & $12.20(3)$ & 62.78 & $16.72(2)$ & 60.56 & $10.70(4)$ & 57.84 \\
\hline
\end{tabular}

Remark: (1) $\mathrm{PV}_{i j}$ stands for the performance value, $i=1,2,3, \mathrm{j}=1,2,3,4$; (2) brackets ( ) stand for "rank"; (3) * SPV stands for Synthetic Performance Value.

Considering SPV, it is: $48.25 \%$ - for $X_{1}, 60.38 \%$ - for $X_{2}$, and $73.10 \%$ - for $X_{3}$. This indicates a low performance recognition and the effect on the FRM activities. Thus, it reveals that the concept of FRM to be effective in a work field, still have large room for improvement.

Table 3. Overall performance measure for each criteria responses

\begin{tabular}{c|cccc|ccc|ccc|ccc|cc}
\hline & \multicolumn{4}{|c|}{ Measuring } & \multicolumn{3}{c|}{ Monitoring } & \multicolumn{3}{c|}{ Controlling } & \multicolumn{3}{c}{ Policy } \\
\cline { 2 - 6 } & A1 & A2 & A3 & A4 & B1 & B2 & B3 & C1 & C2 & C3 & D1 & D2 & D3 \\
\hline \multirow{2}{*}{ Weight } & 0.053 & 0.120 & 0.040 & 0.095 & 0.060 & 0.097 & 0.061 & 0.071 & 0.096 & 0.127 & 0.071 & 0.065 & 0.045 \\
\hline \multirow{2}{*}{$X_{1}$} & 2.72 & 4.82 & 0.74 & 5.06 & 1.53 & 4.97 & 1.91 & 2.63 & 3.14 & 6.98 & 5.61 & 4.49 & 1.85 \\
& $(8)$ & $(5)$ & $(13)$ & $(3)$ & $(12)$ & $(4)$ & $(10)$ & $(9)$ & $(7)$ & $(1)$ & $(2)$ & $(6)$ & $(11)$ \\
$X_{2}$ & 1.63 & 4.72 & 6.56 & 4.84 & 4.26 & 5.64 & 3.28 & 5.60 & 5.62 & 7.36 & 4.57 & 3.47 & 3.27 \\
& $(13)$ & $(7)$ & $(2)$ & $(6)$ & $(9)$ & $(3)$ & $(11)$ & $(5)$ & $(4)$ & $(1)$ & $(8)$ & $(10)$ & $(12)$ \\
$X_{3}$ & 3.39 & 9.32 & 3.93 & 8.29 & 5.07 & 5.48 & 6.01 & 5.70 & 7.51 & 9.34 & 2.63 & 3.00 & 3.35 \\
& $(10)$ & $(2)$ & $(9)$ & $(3)$ & $(8)$ & $(7)$ & $(5)$ & $(6)$ & $(4)$ & $(1)$ & $(13)$ & $(12)$ & $(11)$ \\
\hline \multirow{2}{*}{ Avg. } & 2.58 & 6.28 & 3.74 & 6.06 & 3.62 & 5.37 & 3.73 & 4.64 & 5.42 & 7.90 & 4.27 & 3.66 & 2.82 \\
& $(13)$ & $(2)$ & $(8)$ & $(3)$ & $(11)$ & $(5)$ & $(9)$ & $(6)$ & $(4)$ & $(1)$ & $(7)$ & $(10)$ & $(12)$ \\
\hline
\end{tabular}

As we see from Table 3, the average top five criteria are: security (C3), accuracy (A2), adequacy (A4), completeness (C2), and timeliness (B2). There is strong consistency in respodent opinion as every category ranked the security (C3) as the first. However accuracy (A2) received low rank from the groups $X_{1}$ and $X_{2}$, high rank put by the group $X_{3}$ (almost the same as the (C3)) gives this criterion the strong second position. Besides security (C3) and conciseness (D3), other criteria received differential ranks from different groups and their position is a result of averaging procedure. 


\subsection{Discussion}

From Table 1 and Table 2 content it is clear that the average result and ranking have a positive correlation between weights and satisfaction.

Engineering group puts the highest SPV on FRM, which means their highest satisfaction of the performance. Management demonstrates fair result on recognization of the improtance of FRM. This study also reveals the large gap between expectations and performance presented by finance group. The result confirms that people with engineering background are more likely satisfied with the financial management and they pay less attention financial matters. Usually, top management relies on the reports from finance department to figure out the financial risk status. Obviously, finance related experts provide a highest alert on viewing FRM and provide a more strict vision of the satisfaction of FRM system. However it is unavoidable to ignore the opinion of other groups of interest.

\section{Summary}

Our analysis confirms the opinion that the FRM is an important driver for financial strategies in modern company. Building the stable and intelligent business environment depends on a well-established FRM system. Therefore, the mentioned issues are not only feasible but also of great value for FRM improvement. Besides, FRM process should match external sources of finance and strategies for corporate development. Then, this study provides the average top five criteria for improvement of FRM, which are: security, accuracy, adequacy, completeness, and timeliness. The result also indicates a lowperformance recognition and the effect of the FRM activities. Thus, it reveals that the concept of FRM to be effective in a work field, still have large room for improvement. For efficient business it is important to set up and continuously improve the FRM. Presented approach provides the comprehensive procedure which allows good mathing FRM with the company's needs.

\section{References}

Allen, D. (1994), Strategic Financial Decisions: A Guide to the Evaluation and Monitoring of Business Strategy, London: Kogan Page.

Clarke C.J. and Varma S. (1999), "Strategic Risk Management: the New Competitive Edge," Long Range Planning, 32(4), 414-424.

Mulvey, J.M., Rosenbaum, D. P. and Shetty, B. (1997), "Strategic financial risk management and operations research," European Journal of Operational Research, 97 (4), 1-16.

Mulvey, J.M., Shetty B. (2004) "Financial planning via multi-stage stochastic optimization," Computers \& Operations Research 31, 1-20.

Saaty, T. L. (1980), The Analytic Hierarchy Process: Planning, Priority Setting, Resource Allocation, New York: McGraw-Hill.

Saaty, T. L., and Vargas, L. G. (1980), The Logic of Priorities, Kluwer-Nijhoff: Boston, Massachusetts.

Sylla, R. (2003), "Financial systems, risk management, and entrepreneurship: historical perspectives," Japan and the World Economy 15(4), 447-458.

Tzeng, G. H. (1977), "A study on the PATTERN Method for the Decision Process in the Public System," Japan Journal of Behaviormetrics, 4(2), 29-44. 
Tzeng, G. H. and Shiau, T. A. (1987), "Energy Conservation Strategies in Urban Transportation: Application of Multiple Criteria Decision-Making," Energy Systems and Policy, 11(1), 1-19.

Tzeng, G. H., Shian, T. A. and Lin, C. Y. (1992), "Application of Multicriteria Decision Making to the Evaluation of New Energy-System Development in Taiwan," Energy, 17(10), 983-992.

Tzeng, G. H. and Teng, J. Y. (1994), "Multicriteria Evaluation for Strategies of Improving and Controlling Air-Quality in the Super City: A Case of Taipei City," Journal of Environmental Management, 40(3), 213-229.

Ward, K. and Grundy, T. (1996), "The Strategic Management of Corporate Value," European Management Journal, 14(3), 321-330. 